\title{
Human Resource Outsourcing in Times of Economic Turbulence - a Contemporary Review of Practice
}

\author{
Judit Beregszaszi, MSc \\ HR Practitioner in Business Process Outsourcing, London UK \\ Email: judeberegszaszi@googlemail.com
}

\begin{abstract}
Dieu Hack-Polay, PhD
Senior Lecturer, Department of Management, London South Bank University, UK

Email: hackpod2@1sbu.ac.uk
\end{abstract}

Accepted: December 2, 2011 Published: January 9, 2012

doi:10.5296/ijhrs.v2i1.1250 URL: http://dx.doi.org/10.5296/ijhrs.v2i1.1250

\begin{abstract}
This article reviews developments in human resource outsourcing (HRO) in recent years, particularly in light of the severe economic recession prevailing since 2007. It establishes that companies are increasingly outsourcing routine HR processes, and in some cases, critical HR processes in view to cut costs. The article takes the view that while such a strategy could be viable in the short term, its long-term strategic effectiveness is questionable. This view is founded on widely accepted assumptions that people are critical assets in organizations, thus, commanding that companies maintain a strong hold on vital employee commitment processes. Outsourcing may not be the only valid framework for the future; companies must consider alternatives.
\end{abstract}

Key words: Outsourcing; HRO; economic recession; cost saving; globalization; transaction cost.

\section{Introduction and backgrounds}

The complexity of today's globalized marketplace is not arguable and it is highly probable that tomorrow's marketplace would be even more multifaceted. Consequently, regardless of size, sector and level of internationalization business players encounter the necessity to continuously innovate in order to survive, maintain competitive positions and grow. 
Organizations utilize diverse alternatives in an attempt to adjust to the rapidly changing external environment, outperform competitors and achieve strategic objectives. For several years now outsourcing has been part of the market by which organizations divest the management of some activities to external partners in order to focus on core activities immediately connected with the strategic objectives.

Outsourcing, however, is not a new phenomenon. Certain forms of outsourcing were widely used in the past. Going as far back as the era of the Roman Empire, the collection of taxes was "contracted out" to specific personnel by the empire. The practice of using external personnel to carry out duties therefore has a long history. It had a prominent role worldwide up the industrial revolution when technological advances enabled increased production volume levels and more rapid processes which triggered a paradigm shift from the horizontal relations of partnerships to more complex, vertical integrations with strong internal focus (Kakabadse and Kakabadse, 2002). In the age of cost consciousness of the $20^{\text {th }}$ and $21^{\text {st }}$ centuries, the business model of the extensively internalized, vertically structured enterprises has not been proven to be sufficient to respond to market demands and organizations seek outsider support. This support was mostly in the form of partnerships, mergers, alliances and joint ventures that created hybrid organizations whereby outsourcing deals regained prevalence again (Kakabadse and Kakabadse, 2002).

In the term outsourcing, the first part of the word suggests externality, foreign nature of something, or in other words something that is owned by others. The second part refers to supplements, origins or equipment amongst others. Outsourcing signifies the use of outsider resources to accomplish a task. Outsourcing is a broadly used action across the globe: many businesses opt for this solution in order to supplement, replace, broaden or reduce their operations. It can affect a wide variety of disciplines, including knowledge based functions such as human resources. But just as in every aspect of business, HR outsourcing cannot be seen in isolation and without considering contextual factors (Klaas et al, 2001). The political, economic, social and legal landscape that a business operates in defines the scope of actions that can be taken and shapes the direction of decisions. There are trends in the market and certain patterns emerge in business practice but organizations have different objectives, targets, business plans and strategies to follow hence outsourcing deals are diverse and the related decisions are situationally dependent. For this reason, every outsourcing deal is unique to a business and multifaceted consideration should be made before opting for this solution, which makes the practice increasingly complex in its nature.

There is no agreement whether Human Resource outsourcing (HRO) as a market trend is appropriate or not. There are pros and cons. The main arguments supporting outsourcing underscore the variety of benefits it can offer companies utilizing it such as cost savings, gaining access to further expertise or freeing up capabilities internally to focus on core competencies (Marchington and Wilkinson, 2008; Cooke et al, 2005; Gurney et al, 2009; Ulrich, 1997; Lepak and Snell, 1998). There are similarly several warnings about the potential drawbacks of outsourcing because the benefits may not be so obvious and there are substantial financial consequences; these regard both explicit and implicit costs such as money, time, effort and lost know-how that could counterbalance gains. Not surprisingly, the 
same authors who reported its benefits warn about the limitations and this issue justifies the argument of Klaas et al (2001) that outsourcing is extremely complex. These arguments raise the question of whether HR outsourcing solutions can be used to a business's advantage. The ongoing severe global recession is further evidence that sourcing services from outside of the organization must be the subject of careful strategic consideration. The wide range of opinions results in firms having different drives behind outsourcing deals. While one firm outsources a certain function, the other one would keep that task inside. Some firms contract out only one function, while others opt for outsourcing whole processes in the framework of business process outsourcing. Whether one practice is chosen over another depends on what a firm wants to achieve, e.g. be more cost effective due to budget cuts, source expertise it cannot develop in-house or decrease variable payroll budget. The questions around HR outsourcing are countless which support a strong rationale for further research in the field.

Human Resource Outsourcing (HRO) co-operations are contextually varied and, as such, every organization has different motivation to outsource or not HR tasks. This study has opted to review the reasons that push organizations to consider outsourcing and its validity as an HR model within a slow growth economy such as the global turbulence of the past five years. Once an organization decides to outsource HR, there are many possible approaches. Decisions to source services externally are shaped by many factors depending on contexts. HR deliverables are hard to quantify and consequently its output is difficult to measure even within similar organizational settings. This limitation is amplified when the task or task-sets shift to an external provider over whom only limited control can be exercised. Whether initial expectations are met, exceeded or unmet determines satisfaction levels of the parties and how these perceptions are best assessed is a further objective that this article pursues.

\section{Outsourcing: the theoretical framework}

This section introduces key themes intrinsic to HR outsourcing, commencing with the definition then elaborating on some major theoretical perspectives and contrasting academic and practitioner viewpoints regarding the rationale and justification of what HR areas are frequently subjected to outsourcing. The section equally explores drivers of an increased interest in outsourcing HR functions, benefits that result from it and the drawbacks. The critical review of the existing findings on outsourcing reveals an issue that embraces ambiguity around the definition of outsourcing. A major concern arises from the fact that different types of external service deliveries are often labelled under the term outsourcing despite the several forms this practice can take (Marchington and Wilkinson, 2008).

There is little consensus on what really constitutes outsourcing. As Adler (2003) claims this stems from the complexity and multifaceted factors encompassing the outsourcing phenomenon. Others highlight the blurred borderline between different practices. Gurney et al (2009) see the rather implicit nature of the external service provision and argue that even those practices that tend to be more definite are elastic as they associate different elements with outsourcing. When describing outsourcing practice, some claim that in many aspects outsourcing and sub-contracting are synonyms (Haines, 2009) while others emphasize significant differences between these two terms (Kakabadse and Kakabadse, 2002). The 
definitions usually cover the practice of simple sub-contracting, both short- and long-term but also the divesting of a bundle of activities or even whole processes to external service providers. A simplistic definition has been formulated by Domberger (1998:12) who contends that "outsourcing refers to the process whereby activities traditionally carried out internally are contracted out to external providers". The implication of the external nature of service provision in this definition is complemented with some other aspects that reinforce the complexity of outsourcing in Gurney et al (2005) who emphasized the measurable aspect of outsourcing and described the practice as the delegation of one or more business processes to an external provider, who then owns, manages and administers the selected processes based on defined and measurable performance metrics. As Belcourt (2006) argues, outsourcing constitutes a single direction of the flow of resources from the subcontractor to the organization. She claims that the parties in the outsourcing deals do not share profits and do not have joint financial contributions; consequently these arrangements are distinct from joint ventures, alliances or partnerships.

There are major theories that can be linked to the outsourcing practice which assist in grasping the underlying rationale of certain business management practices, strategic choices and play a significant role in demonstrating techniques and solutions applied in business. Outsourcing is commonly linked with Williamson's (1975) transaction cost theory. The Transaction Cost Economy (TCE) model proposes comparison of the costs incurred by internal production and by buying from the market. Williamson claims that in order to comply with cost-conscious corporate governance strategies the choice of buying should be considered with regards to price as it could offer cheaper solutions than preparing internally. The popularity of this model is highlighted by Klaas et al (2001) who argued that the majority of the HR outsourcing literature drew on Williamson's TCE model. Porter's (1985) concept of the value chain and competitive advantage is also often associated with outsourcing. He claimed that competitive advantage derives from a firm's distinct processes and ability to contribute to the organization's cost advantage and hence create a differentiation basis (Porter, 1985) Drawing on his framework, outsourcing can be seen as a strategically beneficial solution when a process in the value chain can be delivered externally at less cost.

Approaching outsourcing from another angle, Hamel and Prahalad's core competencies are frequently referenced. They argued that competitive advantage stems from management's ability to consolidate skill sets and technology into such competencies that will allow adaptation to changing circumstances. This can be achieved through a "comprehensive pattern of internal coordination and learning" (Hamel and Prahalad, 1990:81) that is difficult for competitors to imitate. Consequently they emphasize that activities considered as core to the business should be performed internally to maintain competitiveness and only functions that are not critical to the business can be divested to external providers so that the organization can focus on more strategic issues. Based on this notion, Oshima et al (2005) suggest that outsourcing is an opportunity for HR to achieve a higher level of business focus and to pursue the HR transformation in a more strategic fashion. Outsourcing as such is utilized for beneficiary motives. However Barney (1991) claims that firms can only gain competitive advantage when they possess rare resources internally, that are hardly 
substitutable. Apart from all types of tangible and intangible assets, these resources include human assets that seamlessly meet the above outlined criterion of being imperfectly imitable and specific to the organization. Barney's theory is referred to as the resource based model. This also implies however, that internal resources are inevitable for securing sustained competitive advantage and that it is unlikely that those can be purchased externally. Thus, the resources that are critical to achieve success are already with the firm and the function itself is path dependent (Cool and Diericx, 1989; Barney, 1991).

\section{What gets outsourced: specialist $v$ generalist and core $v$ non-core}

There are pros and cons as to whether certain practices should be divested or not and the major debate on the subject probably stems from the complexity embracing outsourcing as a business solution (Klaas et al, 2001). Whether a function should be outsourced or not depends on a whole list of factors and characteristics. Klaas et al (2001) found assessing whether a function is considered as specialist or generalist to be of crucial importance when making outsourcing decisions. Klaas and colleagues found that firms utilizing a strategic approach to human resource management are more likely to outsource specialist HR activities over generalist HR activities. This practice derives from the belief that these firms utilize idiosyncratic HRM practices and so, HR generalist activities require specific knowledge which is unlikely to be possessed by external suppliers unless they receive sufficient training. For this reason generalist activities tend to be kept in-house. On the contrary, there are organizations that commonly outsource generalist activities. This is only likely to happen when external expertise is sought in order to fulfil activities that are not related to strategic decisions but represent specialist expertise (Klaas et al, 2001) In this case, outsourcing is considered as an appealing solution, especially in the event of uncertain future market predictions as the burden of risk can be shifted away from the firm. 


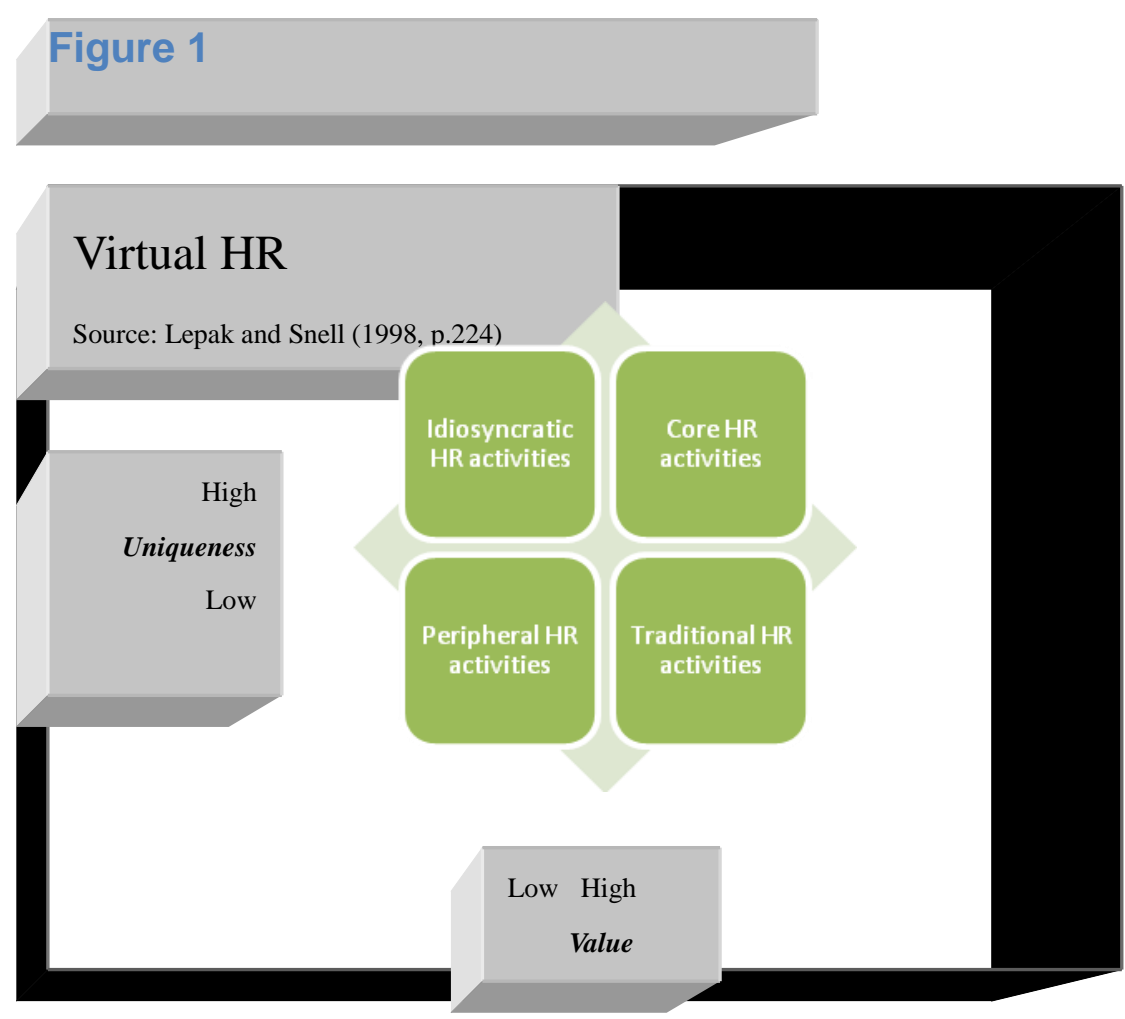

Another body of research emerged that assesses the relation of activities that are potentially subjected to outsourcing with the business. Some are considered as core activities while others are peripheral or non-core, however these characteristics are situationally dependent and vary from one firm to another.

Core activities are considered to be of strategic importance to the business. They are the building blocks of a potential competitive edge hence outsourcing of these activities is strongly discouraged (Adler, 2003). Adler argues that such critical activities should be kept in-house, as they have a significant role in creating and maintaining the firm's sustainable, long-term competitive advantage. He is unequivocal that sensitive functions, activities intrinsic to the firm, value-adding elements of the HR system, that are part of a firm's strategic infrastructure, core activities that constitute uniqueness are better to be pursued internally (Switser, 1997; Gurney et al, 2009; Lepak and Snell, 1998). Only functions that are peripheral, non-core and do not meet the criterion of non-imitability and non-substitutability should be considered to be divested to external providers (Barney, 1991; Lepak and Snell, 1998)

These perspectives do not unconditionally apply in small and medium enterprises (SME) sector. While transactional work is mostly outsourced in larger companies, in small firms HR outsourcing practice is rather different and since all HR often outsourced and this involves their critical activities (Belcourt, 2006; Gurney et al, 2009). Despite consensus amongst academics and practitioners that core functions are better performed internally in the case of large company only peripheral activities should be subjected to outsourcing, some still argue that certain areas traditionally considered as core started to be subjected to heavy 
externalization and that the HR function is "being under siege from external consultants" (Clark and Clark, 1990; Redman and Wilkinson, 2009). Due to the external position of HR service providers they are in a disadvantageous situation, as opposed to internal employees, to make responsible strategic decisions concerning organizational requirements and what can be afforded by them (Hall and Torrington, 1998) hence the critiques.

\section{Figure 2}

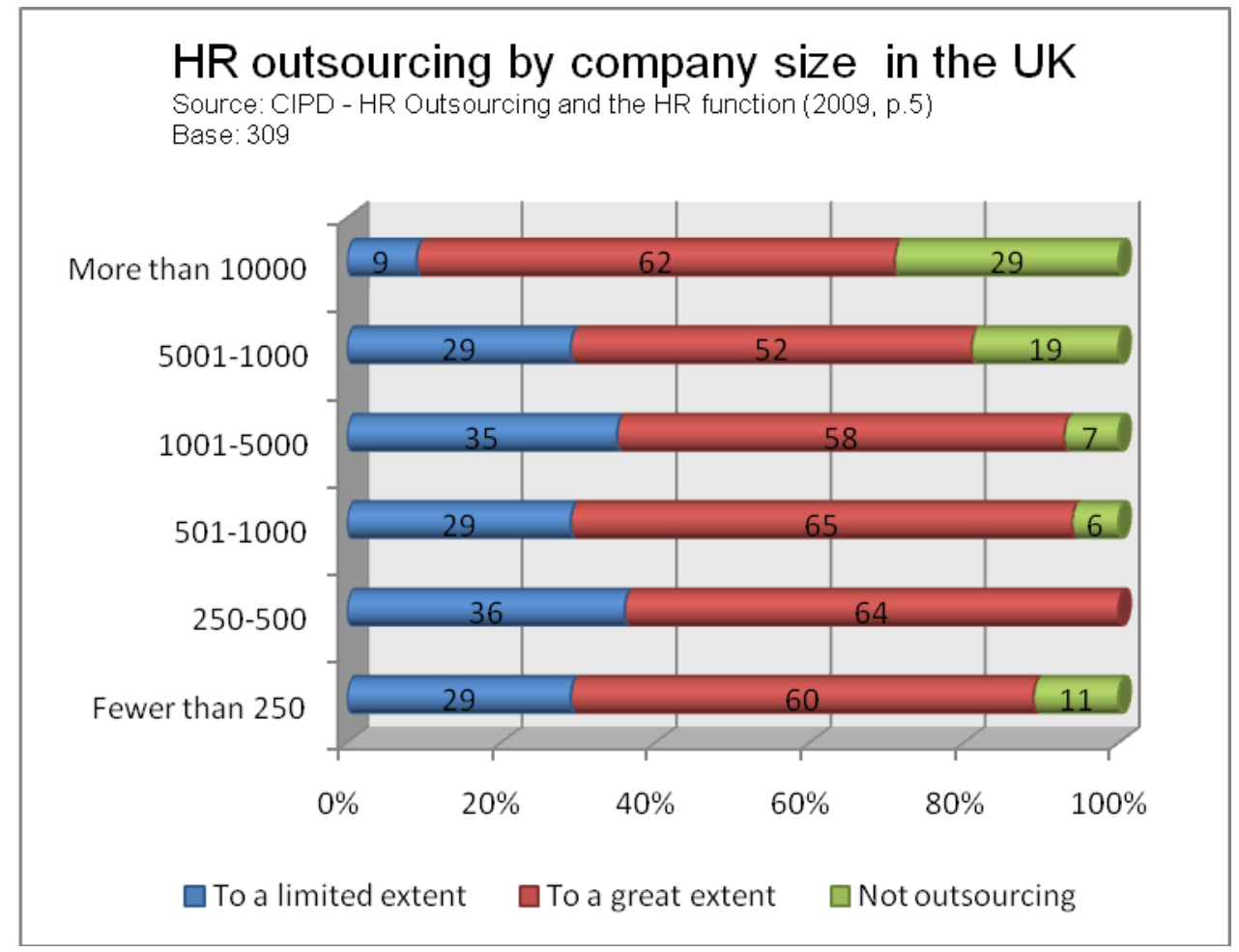

There is some debate about whether there is a clear borderline between core and non-core activities of a firm. Ambiguity and subjectivity embrace this discussion (Legge, 1995; Purcell and Purcell, 1999) as non-core, supporting activities of one firm might be central in another organization. These characteristics are determined by history, external environment and organizational culture and normally constitute management deliverables, organizational strategies and policies, as Cooke et al (2005) propose. These core activities are of critical significance to organizational success by delivering the bottom-line, directly contributing to gaining and sustaining competitive advantage and supporting future growth (Alexander and Young, 1996). The same academics argue that core practices are typically sourced internally hence those areas that constitute someone else's core activities can be considered for outsourcing (Belcourt, 2006). Typically, these are easily replicable, transformational activities that do not deliver unique value to the business (Ulrich, 1998).

\section{Functions typically outsourced or kept in-house}

The view has already been supported already that outsourcing decisions are complex and 
situationally dependent (Klaas et al, 2001) and as a result it cannot be obviously stated whether certain functions should or should not be outsourced stemming purely from their core or peripheral character. Marchington and Wilkinson (2008), however, still claim that certain areas are being more heavily divested than others. Gurney et al (2009) identify HR administration, recruitment and selection, training and record keeping as typically outsourced functions, which they also cluster as transactional activities. Gurchiek (2005) highlight the very common outsourcing practice of outplacement services, EAPs (employee assistance programmes) and the administration of benefits and pensions. Alewell et al (2011) report the existence of common outsourcing practice of external legal advice, temporary agency work and consulting. Cooke et al (2005) view training and development, recruitment and selection, payroll and benefits administration lead the pragmatics of outsourcing while in the Hungarian practice trainings, recruitment, temporary staffing and payroll are the most sought after HR services according to Borda et al (2010) - see figure 3. There is evidence of the commonness of outsourcing certain functions. Recruitment process outsourcing (RPO) is a typical example of external sourcing the management of recruitment and selection (Collings, 2006), a view shared by Ordanini and Silvestri (2008) who consider recruitment and selection as one of the most heavily outsourced HR functions.

\section{Figure 3}



Birtch et al (2010) and Gurney et al (2009) claim that confidential, sensitive functions that bear high strategic importance are typically kept in house, e.g. strategic policy making, development and change management. In addition, the findings of Greer et al (1999) consider employment relations and job evaluation as of being central functions to the organization. Those are not pragmatically outsourced. This derives from the specific nature of the 
management of these activities because to be effective, "consistency, trust and understanding of long-term effects in relationships and control of confidential information" (Greer et al, 1999) are required. Hall and Torrington (1998), however, interestingly found management development, performance management and reward strategies as frequently outsourced functions, opposing to views that consider these activities to be strategic (Gurney et al, 2009; Birtch et al, 2010).

There is much rhetoric about the types of activities outsourced, while comparatively less attention is given to the specific functions. Many of the findings overlap highlighting consensus on the topic; however opposing views also exist. Given the multifaceted nature of outsourcing this perspective is not surprising and gives further support to Klaas et al's (2001) view examined earlier. Situational variables affect the pragmatics, which explains the diversity of viewpoints about the actual benefits of HRO, particularly in times of economic turbulence.

\section{Case for outsourcing in the current economic climate}

In an era of cost consciousness, fierce market competition and innovative solutions, there are several challenges that have the power to significantly shape the world of business. Such forces are varied and may be overlapping. Globalization is one of the top trends that considerably alter the external environment forcing organizations to adapt to its effects (Greer et al, 1999; Snell and Wright, 2005). International expansions, mergers and acquisitions, joint ventures and green-field investment dominate business practice, but along with the global imperative the growing complexity of the regulatory environment, both, on domestic and international platforms is to be noted (Adler, 2003). Increasing pressures for profitability are putting a burden on organizations, which moves typically materialize in strict cost monitoring or cost reducing efforts HR departments are often subjected to (Ulrich, 1998; Greer et al, 1999). Techno-savvy novelties increasingly appear in the business field accelerating processes, improving efficiencies and enabling a higher extent of effectiveness. Keeping up with these improvements is essential for gaining and maintaining a competitive edge even in HR (Snell and Wright, 2005; Ulrich, 1998). Greer et al (1999) report downsizing and restructuring efforts none of which leaves the HR function untouched, while Ulrich (1998) brings to light the growing importance of intellectual capital and the need for effective change management.

The existing literature on the reasons why businesses opt for outsourcing indicates a high level of consensus on breadth. The variety of drivers is often influenced by size of firm, sector, company objectives, strategy, availability of specific skills, organizational changes and other factors (Alewell et al, 2009; Birtch et al, 2010; Klaas et al, 2001). Outsourcing practice is driven by various reasons; however it is essential to note Corbridge and Pilbeam's (2010) recent warning that it should only be treated as a potential opportunity and not as a generic solution for problems. Defining the rationale of the practice in simple terms, its potential can be exploited when "someone else can perform the activity better than you" (Greer et al 
1999:87). Underpinning this notion, Alewell et al (2011) contend that organizations have higher service quality expectations from external providers when outsourcing HR. Financial drivers account for many direct reasons for outsourcing. The recently prevailing cost conscious character of conducting business often posits HR to the periphery. Redman and Wilkinson (2009) go that far in examining this subject that they proclaim HR`s status quo to be in a crisis and they argue that the function needs to cope with diminished legitimacy. Being accepted and taken more seriously at "board level", acting as a strategic partner (Ulrich, 1997; Snell and Wright, 2005) gaining higher status for HR in the organizational value chain and attaining a more strategic role are therefore significant motivations behind outsourcing (Gurney et al, 2009; Cooke et al, 2005; Klaas et al, 2001).

The desire for HR to be strategic is often driven by cost related considerations (Redman and Wilkinson, 2009; Becker and Gerhart, 1996; Gurney et al, 2009). With belt tightening efforts the function is often subjected to budget cuts whereby the delivery of higher value is expected from HR at a lower cost (Adler, 2003). Small companies' outsourcing practice is often linked to cost as a driver because HR practices can be characterised as occasional, with no continuous workload. This results in higher employee cost [relatively high unit cost] as opposed to the cost of HR outsourcing (Abraham and Taylor, 1996; Klaas et al, 2001; Gurney et al, 2009).

Belcourt (2006) underscores that financial saving is the most often cited trigger behind outsourcing decisions. Other authors argue that the majority of firms do not outsource for economic purposes and the rationale for outsourcing decisions are beyond pure cost motives (Birtch et al, 2010; Kakabadse and Kakabadse, 2002). With outsourced solutions a whole host of employee related costs such as overtime, recruitment and training expenses can be reduced, the size of the function can be shrunk and cheaper substitutes be applied, hence the overall payroll expenditure can decrease (Marchington and Wilkinson, 2008; Cooke et al, 2005). By utilizing external services, the know-how is delivered by external staff, which avoids investments of financial capital and consequently leads to economies of scale (Kakabadse and Kakabadse, 2002; Abraham and Taylor, 1996; Klaas et al, 2001). This finding is tightly connected to Williamson's TCE theory: the "make or buy" decision (Williamson, 1975). Under the cost rationale of outsourcing, Gurney et al (2009) draw the attention to the fixed and variable cost lines on the balance sheets which can potentially shift towards the latter one. Reducing the cost centre role of HR is more favourably perceived by senior staff and hence outsourcing has the potential to be welcomed at board level. This can consequently result in the reduction of the HR function's size but empirical evidence shows that a percentage of the affected employees are often taken over by the HR service providers (Gurney et al, 2009). It is beyond the scope of this article to investigate all aspects of rhetoric and reality with regards to this notion.

A further alternative view related to cost savings - based on Domberger's arguments (1998) has been revisited by Cooke et al (2005) who propose that outsourcing has implications on future spending because providers' costs can be kept low by selecting the most beneficial tender. Marchington and Wilkinson (2008), however, warn that despite the benefits, the analysis of hidden and indirect costs of outsourcing should not be forgotten. Many argue that outsourcing is a viable way of minimising risk factors in business by shifting them over to the 
service provider. Cooke et al (2005) propose that this driver is of significant importance in times of uncertainty and unclear future needs and prospects while Greer et al (1999) stress this driver's prevalence amongst small companies that do not have enough resources to maintain a fully informed team and are consequently more prone to risk. Utilizing $\mathrm{HR}$ outsourcing services for SMEs means legal compliance (Belcourt, 2006). An external partner has the potential to deliver capability, knowledge and innovation via the expertise the employees bear, which when bought in by an organization, can tremendously reduce the threat experienced (Gurney et al, 2009) and in many aspects the associated burden of risk can be shifted away from the organization (Cooke et al, 2005). It should be noted that the price of service provision is always carefully calculated, having assessed all factors involved in the deal, including risks the service provider agrees to bear. The extent of uncertainty HRO providers engage in is incorporated in the price and ultimately the organization pays for its reduced risk (Grossman, 2004).

Ulrich (1997) makes a powerful case for HR to attain a value added stance. His HR business partner model supports the creation of a more strategic role for the function by outlining four roles for HR: to be an administrative excellence, employee champion, change agent and strategic partner. But a whole host of other views also support the strategic rationale behind outsourcing (Kakabadse and Kakabadse, 2002; Belcourt, 2006; Cooke et al, 2005) which can drive a change of direction by enabling organizations to concentrate in-house assets on what they are best at, i.e. company core activities (Barney, 1991; Cooke et al, 2005; Gilley et al, 2004; Lepak and Snell, 1998). The major arguments highlight divesting peripheral activities in order for HR to be able to emphasize its more strategic and value adding character. This is to be done by freeing up in-house HR staff to redirect the attention towards attaining a higher profile for the function and performing tasks more directly related to organizational strategies. For Barney's (1991) the rationale of divesting non-core functions with the aim of being able to direct attention to more strategic aspects, even in the case of HR is validly underpinned. Gilley et al (2004) believe that outsourcing of HR functions positively influences organizational performance and promotes innovation, notably in the outsourcing of functions such as training and development. On the contrary, Chiang and Shih (2011) question the validity of such a perspective by claiming that skills gained from external training suppliers cannot be fully integrated in the organization and argue that training outsourcing has no significant impact on effectiveness.

Divesting administrative activities is a helpful way of increasing the strategic edge (Oshima et al, 2005) of the HR function which is often accused of being rather operational and lacking strategic focus (Greer et al, 1999). Outsourcing, however, is just one element involved in becoming more comprehensive. Greer et al (1999) outline the complexity of the practice and that attaining a strategic stance is not necessarily easy to obtain via utilizing outsourcing solely. They claim that strategic initiatives pre-outsourcing also have a role in contributing to successfully achieve required strategic objectives which notion is underpinned by Corbridge and Pilbeam (2010) who consider outsourcing as an opportunity rather than a generic solution. Outsourcing decisions are often driven by the need to access external expertise. Belcourt (2006), Gurchiek (2005) and Greer et al (1999) emphasize the provider's knowledge and the time savings obtainable, while Lepak and Snell (1998) note the "just-in-time" and "ad hoc" 
nature of external specialists that can be utilized as-and-when required without paying for in-house employees on a regular basis. This character can enhance flexibility, as Cooke et al (2005) conclude. Accessing specialised knowledge has significant importance amongst small organizations, which often do not employ anyone in charge of HR until the company reaches a certain size (Belcourt (2006). She claims though that SMEs need to pursue at least some HR activities which often results in HR outsourcing. Even in cases where they employing someone, SMEs do not have the economies of scale to deploy full-scale, high quality HR services in-house which advance outsourcing services (Abraham and Taylor, 1996).

This expertise available can constitute specialised know-how in certain areas and excellence in specific skills (Marchington and Wilkinson, 2008). These are often the core competencies of the vendor who is consequently able to provide high quality service (Alewell et al, 2011; Cooke et al, 2005; Gilley et al, 2004; Greer et al, 1999). Besides drawing on the human capital of the service providers, other assets can be used to the buyer's advantage. Outsourcing, thus, can mean an alternative to accessing a wide variety of technologies without investment for internal implementation (Belcourt, 2006; Haines, 2009; Greer et al, 1999; Adler, 2003; Gurney et al, 2009). Along with the expertise and technology bought in the service levels are expected to increase (Belcourt, 2006; Gurchiek, 2005) and by freeing up internal capacities to deliver added value by focusing on what is deemed to be core for the function, as Cooke et al (2005) argue. The same authors refer to Ulrich's (1997) HR business partner model the implementation of which can be advanced by the liberated HR department through which a strategic contribution can be attained. The process when vendors adapt to an organization can take long and be subject to coordination issues. As such Nikandrou et al (2010) claim, outsourcing has a negative impact on productivity.

Alternatively, authors draw on eluding the internal bias as a potential advantage of outsourcing. Cooke et al (2005) report about the objectivity externals deliver, and Marchington and Wilkinson (2008) stress the independence from influence experienced in house and the broader perspectives available. Further views claim, that the changing psychological contract between employer and employee has led to the perception of a less secure work environment and reduced commitment (Kakabadse and Kakabadse, 2002). This notion is in parallel with the higher mobility of knowledge workers and creates a hotbed for outsourcing. This strategy can be used to management's advantage (Harris and Leopold, 2009). While many findings did not propose any views related to management's previous experiences and being affected by other influences as a motor of outsourcing decisions, Gurney et al (2009) believe past experiences to be influential when opting for outsourcing. Greer et al (1999) advocate that there are several other aspects not examined by others, namely capacity issues whereby HR outsourcing is considered to be a stage in HR's evolution especially when it is being restructured or in the case of small organizations initially developed.

\section{Limitations of HRO and risks in a slow growth economy}

The noticeable benefits and advantages of outsourcing do not exist without potential 
drawbacks. The complexity of the practice has been already emphasized (Klaas et al, 2001) which inevitably involves a high level of risk factors and shortcomings. There is as much consensus about limitations as there is about advantages. Outsourcing practices with cost reducing intentions are prevalent but Gilley et al (2004) note that outsourcing of HR activities does not affect short term financial performance and that the cost involved is often higher than anticipated (Belcourt, 2006; Adler, 2003; Gurney et al, 2009). This can result from some hidden financial implications such as potential increased training and development costs spent on in-house HR (Gurney et al, 2009), or in the case of idiosyncratic approaches disappointing achievements in economies of scale due to additional investments which disadvantageously affect financial savings expected from outsourcing (Klaas et al, 2001). These unanticipated new costs can be difficult to manage (Marchington and Wilkinson, 2008). The opportunity to reduce the headcount via outsourcing during the economic recession is deemed to be a short-term solution because immediate savings do not necessarily have long-term effects on productivity, efficiency and stability (Haines, 2009).

Outsourcing in general can be considered a potential source of lost core competencies when firms externalize functions considered as cost centres (Hamel and Prahalad, 1990). Adler (2003) has less radical views in this sense, in a similar vein he only talks about weakening on core competencies, not about losing them completely. Another body of research builds on the knowledge lost as a result of outsourcing. Haines (2009) emphasises the difficulty of knowledge transfer to the external vendor especially the implicit tacit knowledge which often disappears in outsourcing deals. Gurney and colleagues (2009) formulate this extinction of in-house expertise as losing the "corporate memory" because external suppliers lack sufficient knowledge about organizational culture and past practices (Marchington and Wilkinson, 2008). The loss of expertise and skills can have an adverse impact on organizational competitiveness (Cooke et al, 2005), increase its dependency on external parties (Adler, 2003; Marchington and Wilkinson, 2008) and reduce the ability to maintain internal synergy and creativity (Belcourt, 2006). Outsourcing HR functions can similarly impede career development as it deprives employees of the possibility of gaining expertise through a broad range of activities as those no longer lie with the organization on a full scale (Marchington and Wilkinson, 2008; Greer et al, 1999).

Outsourcing is often claimed to have impeding effects on flexibility regarding strategic decisions (Adler, 2003). Having HR functions externalized might put the firm in a position whereby it cannot respond to organizational needs due to lost control over the externalized functions (Lepak and Snell, 1998). The authors argue that this loss of control derives from firms being restricted by signed arrangements which limit flexibility and makes supporting strategic organizational objectives difficult. Several arguments emphasize the quality of the service provided by the external vendor as of being unsatisfactory. Cooke et al (2005) propose that this stems from the disrupted service continuity and as a result the service delivered falls short of the quality promised or expected (Adler, 2003; Albertson, 2000; Cooke et al, 2005). On the other hand, Greer et al (1999) account this to the primary interest in cost savings which results in the lower quality service. Examining internal expectations though, the landscape can remain bleak and expectations are not necessarily met. The intention of freeing up internal staff to focus more on strategic issues is argued to be below 
anticipations (Cooke et al, 2005) and as Albertson (2000) points, only some firms are able to increase strategic focus and do not devote less time to the old responsibilities either. Being a form of restructuring, HR outsourcing often results with the reduction of the HR function (Belcourt, 2006). As a result, outsourcing affects workplace culture, performance (Klaas et al, 2001) and has a potential negative impact on employee morale. Haines (2009) and Kakabadse \& Kakabadse (2002) propose an alternative view as to why this might happen; they suggest that the social contract is not encouraging anymore and thus results in diminished commitment and job security.

\section{Scope of the outsourcing marketplace during the economic recession}

Parallel with the notion of "outsourcing fever" and the "offshore boom" the number of service providers rises (Marchington and Wilkinson, 2008). These authors claim that some external partners meet or exceed standards while others fall short on expectations. Drawing on the general outsourcing practice Haines (2009) examined closely the concept of outsourcing HR practices in particular. He drew a distinction between HR Business Process Outsourcing (HR BPO), Professional Employer Organizations (PEOs), Application Service Providers (ASPs) and e-services. Such deals are considered as HR BPOs in which the service provider offers end-to-end HR services and the buyer utilizes these integrated services on more of its HR functions, i.e. devolves those practices to the HR BPO provider to be fully managed (Berkshire, 2004). Haines (2009) argues that under HR BPO further approaches can be noted, such as the spin-offs, outsourcing to an external organization and shared service centres with the latter being possibly sourced either internally or managed by a third party (Redman and Wilkinson, 2009). The typical practice of outsourcing recruitment and selection activities has led to the emergence of a further HR BPO subcategory, the Recruitment Process Outsourcing (RPO) or people`s employment outsourcing (Redman and Wilkinson, 2009; Haines, 2009; Ordanini and Silvestri, 2008).

Professional employer organizations are HR service providers that do not just recruit and select but also employ the workers carrying out tasks for a third party. On the contrary this practice is referred to as contingency working by others (Fisher et al, 2008), the underlying idea of which is that the "end-user" pays for the work as a service and not as payroll expense. In opposition to Haines' views the term PEO has been used differently by other authors, who define these types of service providers as firms that deliver services that enable organizations to engage more in differentiation, deal with complexity and respond to technological and market changes (Lepak and Snell, 1998). PEOs competencies reside in value-adding HR services that experienced HR staff deliver (Basso and Shorten, 2009). This character of PEOs accounts for Ordanini and Silvestri's belief (2008) that if core HR functions are outsourced, they are classically outsourced and the outsourcing market is showing a growing trend in the number of PEOs concurrently (Lepak and Snell, 1998; Basso and Shorten, 2009). Haines' ASPs model (2009) rests on the idea of renting HR applications or software programmes to buyers that they can use to manage a host of HR related tasks.

Other academics classify outsourcing along different patterns. Marchington and Wilkinson 
(2009) sort outsourcing providers by size. Global companies have the competencies to even take over full HR functions including the strategic aspects of human resources, but total HR services are also offered by smaller consultants, targeted at small firms. Empirical evidence shows that outsourcing full HR is not prevalent amongst large companies, but on the contrary SMEs often turn to this solution and they almost solely constitute the recipient category of full scale HR outsourcing services (Belcourt, 2006; Gurney et al, 2009). Adler (2003) contends that with the increase of HR outsourcing practice three types of HR service providers emerge. He clusters them as consultants, (1) who offer expertise in certain areas, e.g. administrative service providers, (2) who take over routine tasks, and (3) technology enablers who implement, maintain and -or- manage HR systems. These diverse arguments support the perspective that there is little consensus in conceptualizing outsourcing and that there are many overlapping intersections of the different explanations.

\section{Conclusion}

Several aspects of outsourcing practice have been highlighted so far, but little has been said about how results are assessed and how joint satisfaction is measured, both of the vendor's and the buyer's. Marchington and Wilkinson (2008) emphasize the difficulties associated with the measurement of HR's results, given the less quantifiable nature of the function. They contrast it with the assessment of other activities that are mostly measured by performance indicators but HR output is less simply defined and evaluated. This applies to in-house HR and external service provision. The assessment of the latter meets multiple obstacles. Greer et al (1999) outline that needs of both parties should be expressed including performance objectives and evaluation criteria prior to commencement of service delivery. This belief is in line with Gartner's definition of outsourcing, which emphasises the essentiality of "defined and measurable performance metrics" in the practice (in Gurney et al, 2005:1) but no explicit explanations are given. Cooke et al (2005) argue for the development of a "comprehensive model" to measure effectiveness of the outsourcing deals; however, they do not define what that means and leave unanswered the question of how the vendor-buyer relationship should be effectively managed and what control should be in place for effectiveness. Cooke et al offer some best practices such as clarifying expectations, finding the right supplier, efficiency in managing the change, exercising control throughout delivery and establishing long-term partnership to ensure success. In addition, the authors highlight incorporating financial and non-financial elements, assessing direct and indirect costs and focusing on both, short and long term aspects in the feedback loop but do not offer explicitly defined ideas, nor do other academics. While many emphasize the complexity of managing network-based HR structures, the existing literature on how the pragmatics should be done is criticised (Lepak and Snell, 1998; Cooke et al, 2005).

The criticality of the evaluation of vendor-buyer relationship and the measurement of success is evidenced but limited empirical research exists on the subject. The explanations and solutions offered are implicit in nature and questions on how outsourcing relationships should be managed and the results assessed are yet to be addressed. There are numerous viewpoints 
on the validity of outsourcing as a HR process and there is much rhetoric. Different authors define outsourcing in diverse ways. Though they all perceive the external nature of service provision, some argue that sub-contracting is a form of outsourcing while others classify divesting only whole processes as outsourcing. When trying to explain the underlying reasoning for HR outsourcing as a business model and the connected management behaviour, concepts like Williamson's transaction cost economy model, Porter's competitive advantage (1985), Hamel and Prahalad's core competencies (1990) and Barney's (1991) resource based view of the firm are typically referred to. Mostly specialist and non-core functions are externalized because these may not involve strategic intervention by external agencies. The cluster of SMEs differs in this sense; they often utilize HR outsourcing concerning transformational activities as opposed to large companies. It has been noted how influential contextual factors are in HR outsourcing arrangements and, as such, functions subjected to outsourcing are varied, depending on whether those constitute an organization's core or not.

Globalization and complex changing political, economic, social and technological (PEST) environments create the need for responsive management practices, which notion advocates the case for HR outsourcing. The literature highlights cost related considerations, attempts to ease the burden of risk, strategic motivations, accessing expertise, affording technology, eluding internal bias, drawing on past experiences and capacity issues as the major triggering decisions to outsource. Despite several benefits available, the shortcomings of the practice can be felt, for example unforeseen financial implications of outsourcing, the loss of organizational memory, the higher dependency on external parties, a potential unsatisfactory service quality and negative implications for workplace culture.

When attempting to classify HR outsourcing practices by type, overlapping intersections appear to exist in the different categories. The major classifications include clustering like Business Process Outsourcing, Professional Employer Organizations, Application Service Providers, Software as a Service, Recruitment Process Outsourcing or alternatively by the type of activity HR service providers deliver, e.g. consultancy, operative service provider and technology enabler. The effectiveness of the practice is difficult to measure given the non-quantified nature of the function. Articulating objectives, establish the criteria of assessment including financial measurements, focusing on both short and long term factors so that control can be exercised are considered to be critical elements in the assessment process. A comprehensive model of assessment is not easy to create but difficult to define as a consequence of issues of measurability in the discipline and the complexity involved in managing network based HR structures.

Despite the pressures of the current economic realities dominated by sharp recession and commanding reduction in spending, organizations must not see outsourcing as explanatory fetishism. Outsourcing is just one of the many practices organizations can utilize to gain expected benefits but there are alternatives closely related to outsourcing. Shared service centres (SSCs) are claimed to be structurally similar to outsourcing (Marchington and Wilkinson, 2008); however the HR service is delivered from employees of the organization, mostly comprising consultancy responsibilities and transactional work (Gurney et al, 2005). Marchington and Wilkinson (2008) describe SSCs as inter-organizational units that provide services to a network of the same organization. This service can take three forms, first being 
solely internal, second delivering services to external businesses but remaining an in-house function and third, supplying services to a wide network of externals. IT advances accelerate the utilization of computer based systems (Grossman, 2004). Software as a Service (SaaS) is a broadly used practice based on the notion that computer-enabled programmes are licensed to an organization which enables them to fulfil tasks internally cheaper, quicker or more effectively. SaaS can substitute the traditional model of outsourcing (Baca, 2009). Some claim that offshoring is different to outsourcing. Gurney et al (2005) explain that offshoring is an alternative by which services are delivered to the organization from a unit based abroad that is established for this purpose; however the underlying idea is rather similar to that of outsourcing. The main difference is that it operates beyond national borders. Corbridge and Pilbeam (2010) argue that since there is no clear consensus in the utilization of the many modern HR practices the plausible attitude to take is that "what matters is what works".

\section{References:}

Abraham, K.G. and Taylor, S.K. (1996) Firm's use of outside contractors: Theory and evidence. Journal of Labour Economics, 14, pp.394-424

Adler, P.S. (2003) Making the HR outsourcing decision, MIT Sloan Management Review, 45(1), pp.53-60

Albertson, D. (2000) Outsourcing shows limited impact for strategic HR. Employee benefit news, 14(10) pp.70-70

Alewell, D., Braun, I., Pull, K., Störmer, S. and Thommes, K. (2011) HR outsourcing and service quality: Theoretical framework and empirical evidence, Personnel Review, 40(3), pp.364-382

Alewell, D., Hauff, S., Thommes, K. and Weiland, K. (2009) Triggers of HR outsourcing decisions - An empirical analysis of German firms, The International Journal of Human Resource Management, 20(7) pp.1599-1617

Alexander, M. and Young, D. (1996) Strategic outsourcing, Long Range Planning, 29(1) pp.116-119

Baca, F. (2009) Considering HR outsourcing? Consider SaaS, Financial Executive, 25(8), pp. $59-60$

Barney, J. (1991) Firm resources and sustained competitive advantage, Journal of Management, 17(1), pp.99-120

Basso, L. and Shorten, B. (2009) Growing PEO industry continues to raise its standards, $C P A$ Journal, 79(10), pp.10-11. 
Becker, B. and Gerhart, B. (1996) The impact of human resource management on organizational performance: Progress and prospects, Academy of Management Journal, 39(4), pp.779-801.

Belcourt, M. (2006) Outsourcing: the benefits and the risks, Human Resource Management Review, 16(2), pp.269-279

Berkshire, J.C. (2004) Seeking full partnership, HRMagazine, 49(7), pp.88-96

Birtch, T.A., Chiang, F.F.T. and Chow I.H-S. (2010) Examining human resource management outsourcing in Hong Kong, The International Journal of Human Resource Management, 21(15) pp.2762-2777

Borda, V.; Molnár, D.; Juhász, G., Szendrő, K. and Vojtek, É. (2010) HR tevékenységek kiszervezésének értékelő kutatása. Human Exchange Alapítvány: VUPE $2008 \mathrm{Kft}$

Chiang, Y-H. and Shih, H-A. (2011) Exploring the effectiveness of outsourcing recruiting and training activities, and the prospector strategy's moderating effect, The International Journal of Human Resource Management, 22(1) pp.163-180

Clark, I. and Clark, T. (1990) Personnel management and the use of executive recruitment consultancies, Human Resource Management Journal, 1(1) pp.46-62

Collings, J. (2006) Defining RPO in the European market, HRO Europe, 3 (4). [Online]. Available from: http://www.hroeurope.com/ [Accessed: 16/10/2010]

Cooke, F.L.; McBride, A. and Shen, J. (2005) Outsourcing HR as a competitive strategy? A literature review and an assessment of implications, Human Resource Management, 44(4) pp.413-432

Cool, K. and Diericx, I. (1989) Asset stock accumulation and sustainability of competitive advantage, Management Science, 35(12) pp. 1504-1513.

Corbridge, M. and Pilbeam, S. (2010) People resourcing and talent planning: HRM in practice. $4^{\text {th }}$ ed. Harlow: Pearson

Domberger, S. (1998) The contracting organization. Oxford: OUP.

Fisher, S.L., Wasserman, M.E. Wears, K.H. and Wolf, P.P. (2008) Human resource issues in outsourcing: Integrating research and practice, Human Resource Management, 47(3), pp. 501-523

Gilley, K.M., Greer, C.R., and Rasheed, A.A. (2004) Human Resource Outsourcing and organizational performance in manufacturing firms, Journal of Business Research, 57(3) pp.232-240 
Greer, C.R., Gray, D.A. and Youngblood, S..A. (1999) Human resource management outsourcing: The make or buy decision, Academy of Management Executive, 13(3), pp. $85-96$

Grossman, R.J. (2004) Sticker shock, HRMagazine, 49(7), pp.78-86

Gurchiek, K. (2005) Record growth in outsourcing of HR Functions, HRMagazine, 50(6) pp.35-38

Gurney, M., Newham, T. and Scott-Jackson, W. (2005) HR Outsourcing: The key decisions, London: CIPD

Gurney, M., Newham, T., Scott-Jackson, W. and Woodall, J. (2009) Making the decision to outsource Human Resources, Personnel Review, 38(3), pp.236-252.

Haines, R. (2009) Organizational outsourcing and the implications for HRM, in: Collings, D.G. and Wood, G. (eds.) Human resource management: A critical approach. Oxon: Routledge

Hall, L. and Torrington, D. (1998) The human resource function: The dynamics of change and development. London: Financial Times-Pitman Publishing

Hamel, G. and Prahalad, C.K. (1990) The core competence of the corporation, Harvard Business Review, 68(3), pp.79-89

Harris, L. and Leopold, J. (2009) The strategic managing of human resources. $2^{\text {nd }}$ ed. Harlow: Pearson

Kakabadse, A. and Kakabadse, N. (2002) Trends in outsourcing: Contrasting USA and Europe, European Management Journal, 20(2), pp.189-198

Klaas, B.S., McLendon, J.A. and Gainey, T.W. (2001) Outsourcing HR: the impact of organizational characteristics, Human Resource Management, 40(2), pp.125-38

Legge, K. (1995) Human resource management: Rhetorics and realities. London: Macmillan.

Lepak, D.P. and Snell, S.A. (1998) Virtual HR: Strategic human resource management in the $21^{\text {st }}$ century, Human Resource Management Review, 8(3), pp.215-234.

Marchington, M. and Wilkinson, A. (2008) Human resource management at work: People management and development. $4^{\text {th }}$ ed. London: CIPD.

Nikandrou, I., Panayotopoulou, L.and Papalexandris, N. (2010) The choice between internalization and externalization of employment and its impact on firm performance: Evidence from five south-eastern European countries, The International Journal of Human Resource Management, 21(14) pp.2547-2567 
Ordanini, A. and Silvestri, G. (2008) Recruitment and selection services: Efficiency and competitive reasons in the outsourcing of HR practices, The International Journal of Human Resource Management, 19(2), pp.372-389

Oshima, M., Kao, T. and Tower, J. (2005) Achieving post-outsourcing success, Human Resource Planning, 28(2), pp.7-11

Porter, M.E. (1985) Competitive strategy: Techniques for analysing industries and competitors. New York: Free Press

Purcell, K. and Purcell, J. (1999) Insourcing, outsourcing and the growth of contingent labor as evidence of flexible employment strategies. Bulletin of Comparative Labor Relations, 35, pp.163-181

Redman, T. and Wilkinson, A. (2009) Contemporary human resource management: Text and cases. $3^{\text {rd }}$ ed. Harlow: Pearson

Switser, J. (1997) Trends in human resource outsourcing, Management Accounting, 79 (5), pp. $22-24$

Snell, S.A. and Wright, P.M (2005) Partner or guardian? HR`s challenge in balancing values, Human Resource Management, 44(2), pp.177-182

Ulrich, D. (1997) Human resource champions. Boston: Harvard Business School Press

Ulrich, D. (1998) A new mandate for human resources, Harvard Business Review, 76(1), pp.124-134

Williamson, O.E. (1975) Markets and hierarchies: analysis and antitrust implications. London: Collier Macmillan. 